\title{
Propriedade coletiva e regularização fundiária: o caso da usucapião Especial urbana coletiva da Chácara do Catumbi na cidade do Rio de Janeiro
}

\author{
Collective ownership and land regularization: the case of \\ Chácara do Catumbi collective urban special adverse \\ possession in the city of Rio de Janeiro
}

Rafael Soares Gonçalves [a] [D, Josiane do Vale [b] [D]

[a] Pontifícia Universidade Católica do Rio de Janeiro (PUC-Rio), Departamento de Serviço Social, Laboratório de Estudos Urbanos E Socioambientais (LEUS), Rio de Janeiro, RJ, Brasil

Como citar: Gonçalves, R. S., \& Vale, J. (2021). Propriedade coletiva e regularização fundiária: o caso da usucapião Especial Urbana Coletiva da Chácara do Catumbi na cidade do Rio de Janeiro. urbe. Revista Brasileira de Gestão Urbana, v.13, e20200064. https://doi.org/10.1590/2175-3369.013.e20200064

\section{Resumo}

0 presente artigo tem como finalidade suscitar o debate sobre o comum no contexto fundiário, assim como os temas da informalidade urbana e da propriedade coletiva no Brasil, baseado em pesquisa-ação sobre o processo de registro da Usucapião Especial Urbana Coletiva da Chácara do Catumbi, pequena localidade situada no bairro do Catumbi (Rio de Janeiro). 0 presente trabalho estuda os desafios da gestão de propriedades coletivas no contexto brasileiro, analisa o debate em torno do comum em questões envolvendo os direitos de propriedade e, por fim, debate os principais desafios da gestão coletiva da propriedade através do caso da Chácara do Catumbi.

Palavras-chave: Propriedade coletiva. Regulação Fundiária. Usucapião coletiva. Chácara do Catumbi.

\begin{abstract}
The purpose of this article is to stimulate debate on the common in the land context, as well as the issues of urban informality and collective property in Brazil, based on action-research on the registration process of Special Urban Collective Usucaption at the Chácara do Catumbi, a place located at the Catumbi neighborhood (Rio de Janeiro). This paper studies the challenges of collective property management in the Brazilian context, analyzes the debate around the common in issues involving property rights, and finally discusses the main challenges of collective property management through the case of the Chácara do Catumbi.
\end{abstract}

Keywords: Collective ownership. Land regularization. Collective adverse possession. Chácara do Catumbi. 


\section{Introdução}

Observa-se, nos últimos anos, um verdadeiro "renascimento dos comuns" (Bollier, 2014). Essa discussão ganhou corpo, inicialmente, com os trabalhos de Elienor Ostrom (1990), que mostraram a diversidade e riqueza da gestão coletiva de recursos naturais, questionando a ideia da tragédia dos comuns evocado por Hardin (1968). Como sublinha Mendes (2012, p. 19), o desastre, para Hardin, refere-se tão somente ao comum e ao sistema de organização social que se organiza por uma "ética de compartilhamento". Assim, formas de gestão coletiva de recursos foram sendo desacreditadas para proteger tais recursos de um pretenso uso irresponsável. A ênfase foi dada à propriedade privada sob rígida normatização estatal em detrimento de práticas coletivas. 0 retorno da reflexão sobre os comuns se voltou para formas de gestão dos recursos naturais, tendo influenciado inclusive políticas de cunho ambiental, como por exemplo a inserção de Unidades de conservação de uso sustentável no Sistema Nacional de Unidades de Conservação.

O presente artigo pretende discutir mais especificamente a reflexão do comum no contexto fundiário e urbano a partir de uma pesquisa-ação de acompanhamento do processo de regularização fundiária da Chácara do Catumbi, pequena localidade situada no bairro do Catumbi, ao pé do Morro da Mineira na cidade do Rio de Janeiro, que foi definitivamente titulada com a inscrição no Registro Geral de Imóveis em abril de 2018. Os moradores receberam o título coletivo do terreno e benfeitorias que ocupam, após a sentença declaratória da usucapião especial coletiva urbana de maio de 2017. A ação foi proposta em 2006 pela Fundação Centro de Defesa dos Direitos Humanos Bento Rubião. Tendo em vista a dificuldade financeira da mencionada fundação em manter o patrocínio da causa, a Pastoral de Favelas da Diocese Católica Romana do Rio de Janeiro assumiu a causa alguns meses antes da sentença definitiva ${ }^{1}$.

Após a sentença, a Pastoral de Favelas propôs um projeto de assessoria técnica (projeto ATHIS) junto ao Conselho de Arquitetura de Urbanismo - CAU (chamada pública no02/2018 do CAU) com o objetivo de realizar, através de um amplo processo participativo dos moradores, um estudo social e urbanístico para a futura redação da convenção do condomínio especial formado após o registro da sentença de usucapião. Sublinha-se o aspecto inovador do projeto, já que não há indícios de registros de convenção de condomínio especial no país.

\section{Procedimentos metodológicos da pesquisa}

No contexto de um projeto internacional mais amplo sobre os comuns fundiários², o primeiro autor decidiu analisar o processo, que conduziu à titulação dos moradores da Chácara do Catumbi. Tendo em vista o início do projeto de Assessoria Técnica mencionado acima, o primeiro autor convidou a segunda autora, assistente social, para assumirem a equipe social do referido projeto (um advogado/historiador, uma assistente social e uma estudante de Serviço Social), responsável em traçar o perfil socioeconômico da população residente, estimular a participação no decorrer das atividades e levantar informações da história local e do cotidiano dos moradores para a redação da convenção do condomínio. Essa equipe ficou responsável por organizar e aplicar um questionário socioeconômico e estimular a participação dos moradores ao projeto. Para isso, fomos inseridos no grupo local de Whatsapp dos moradores, o que se tornou mais um espaço privilegiado de observação das interações entre os moradores.

Além da equipe social, o projeto contou com a participação da equipe da Pastoral de Favelas (uma advogada e uma agente pastoral) e com a equipe de arquitetura, composta por 4 arquitetos e uma estudante de arquitetura. Esta última equipe exerceu funções relacionadas à caracterização das estruturas físicas de

\footnotetext{
${ }^{1}$ A Pastoral de Favelas foi criada em 1977 no contexto da tentativa de remoção da favela do Vidigal. O seu Serviço de Assistência Jurídica foi muito atuante (Brum, 2018). Diante das pressões internas da Igreja contra a linha mais progressista da pastoral, parte de seus membros decide fundar a Fundação Centro de Defesa dos Direitos Humanos Bento Rubião, em 1986. Se a Fundação Bento Rubião apresenta dificuldades financeiras para manter sua atuação, a Pastoral de Favelas vem procurando, de forma mais tímida do que no final dos anos 1970, atuar novamente na assessoria jurídica dos favelados.

2 Projeto de pesquisa comparada financiado pela Agência francesa de Desenvolvimento (AFD), coordenado por Eric Denis (CNRS), cujo título é Communs fonciers urbains pour l'habitat dans les Suds.
} 
cada edificação na área com a medição das casas e dimensionamento de áreas comuns, assim como procurou identificar possíveis problemas nas construções realizadas pelos moradores. Além das construções, foram demarcadas as áreas comuns (vias internas, áreas de lazer, estacionamentos), assim como os espaços de uso específico de cada moradia.

Como evocado por Thiollent (2011, p. 26), a pesquisa-ação visa organizar conceber e organizar uma pesquisa social de finalidade prática e que dialogue com as exigências próprias da ação e conte com a participação dos atores da situação observada. Assim, procuramos sistematizar os dados obtidos no campo através da observação participante das reuniões da equipe e com os moradores, assim como sistematizamos os dados obtidos nos questionários socioeconômicos aplicados junto aos moradores e nos documentos levantados e produzidos pelo próprio projeto ATHIS.

Dos 23 proprietários locais, aplicamos 20 questionários entre o mês de abril a julho de $2019^{3}$. Além das informações sobre as condições socioeconômicas dos moradores, o questionário possuía algumas questões abertas sobre a história do local e os desafios na organização do condomínio. Não gravamos essas respostas, só as anotamos no formulário e em diário de campo. A conversa se prolongava muito além das questões dos questionários, o que nos permitiu traçar a memória coletiva (Halbwachs, 2006) dos moradores sobre o local onde habitam. Dentre as entrevistas, dois moradores se revelaram mais atuantes na reprodução dessa memória e acabaram se tornando nossos principais interlocutores: Lucio, homem de meia idade e muito atuante entre os moradores, e Carla, que nos forneceu um conjunto de documentos sobre o local (petições dos moradores a políticos, fotos, reportagens...), organizado pelo seu falecido marido ${ }^{4}$ e que nos permitiu traçar o histórico recente da luta dos moradores.

Realizamos inúmeras visitas durante o projeto para conhecer o local e aplicar os questionários e participamos de 6 reuniões com os moradores. Realizamos, nessas reuniões, inúmeras dinâmicas: i) debates, ii) maquetes e mapas mentais coletivos da localidade e iii) caminhadas comentadas pelos moradores, para identificar possíveis problemas na gestão coletiva, assim como levantar proposições para a futura convenção de condomínio. Obtivemos documentos variados junto aos moradores, assim como aos órgãos administrativos (secretaria municipal de urbanismo e registro geral de imóveis). Esses documentos foram digitalizados e disponibilizados para uso de toda a equipe do projeto em um drive na internet.

Quadro 1 - Reuniões realizadas durante o projeto

\begin{tabular}{|c|c|c|}
\hline & eunião inicial \\
\hline & & entação da equipe e da metodologia de trabalho \\
\hline \multirow[t]{2}{*}{2.} & 04.05.2019 & Reunião sobre as formas de participação e de decisão coletiva \\
\hline & & $\begin{array}{l}\text { Buscou-se entender a dinamica de organızaçao dos moradores para resolver as questoes } \\
\text { coletivas. Proposta de criação da Comissão de Mobilização dos moradores para atuar } \\
\text { durante o projeto. }\end{array}$ \\
\hline \multirow[t]{2}{*}{3} & 18.05 & Reunião sobre regularização fundiária \\
\hline & & $\begin{array}{l}\text { posição técnica sobre temas relacionados à questão Urbana: Estatuto da Cidade, leis } \\
\text { derais, Usucapião Coletiva e Condomínio Especial. Avaliação dos moradores sobre as } \\
\text { jalidades, dificuldades e o que desejam em relação ao local (ver figura 1). }\end{array}$ \\
\hline \multirow[t]{2}{*}{4} & 01.06 .2019 & Reunião para a definição dos espaços de uso privado e coletivo \\
\hline & & $\begin{array}{l}\text { coletivo com os moradores na localidade para definir os limites dos } \\
\text { e privado. }\end{array}$ \\
\hline & 13.06.2019 & Reunião sobre as normas coletivas de convivência e de uso e ocupação do solo \\
\hline & & $\begin{array}{l}\text { Divulgação parcial dos dados obtidos através das visitas técnicas; } \\
\text { problemas construtivos; discussão sobre regras para uso dos espaços colet } \\
\text { Reunião de apresentacão dos resultados e perspectivas futuras }\end{array}$ \\
\hline & & $\begin{array}{l}\text { Apresentação clássica de plantas e dados obtidos no pr } \\
\text { representantes da Pastoral de Favelas e do Conselho de Arquitetu }\end{array}$ \\
\hline
\end{tabular}

Fonte: Dados compilados pelos autores.

\footnotetext{
${ }^{3}$ Não conseguimos agendar com duas famílias. O terceiro morador não aceitou preencher o questionário, assim como não participava de nenhuma atividade do projeto.

${ }^{4}$ Os nomes aqui citados são fictícios para guardar o anonimato de nossos interlocutores.
} 
O projeto ATHIS durou seis meses, de fevereiro a julho de 2019, e procurou produzir dados para subsidiar a redação da convenção de condomínio especial. Além do recenseamento local e mapeamento das construções e áreas comuns, o projeto procurou estimular a construção coletiva das normas internas de convivência e uso e ocupação do solo. Buscou ainda fornecer os dados necessários para que se pudesse, em um projeto posterior, redigir e registrar o condomínio. Mesmo sem recursos, a Pastoral de Favelas pretendia retomar o projeto em 2020 com voluntários, inclusive com a participação dos autores do presente artigo, mas a pandemia impossibilitou, por enquanto, a retomada dos trabalhos.

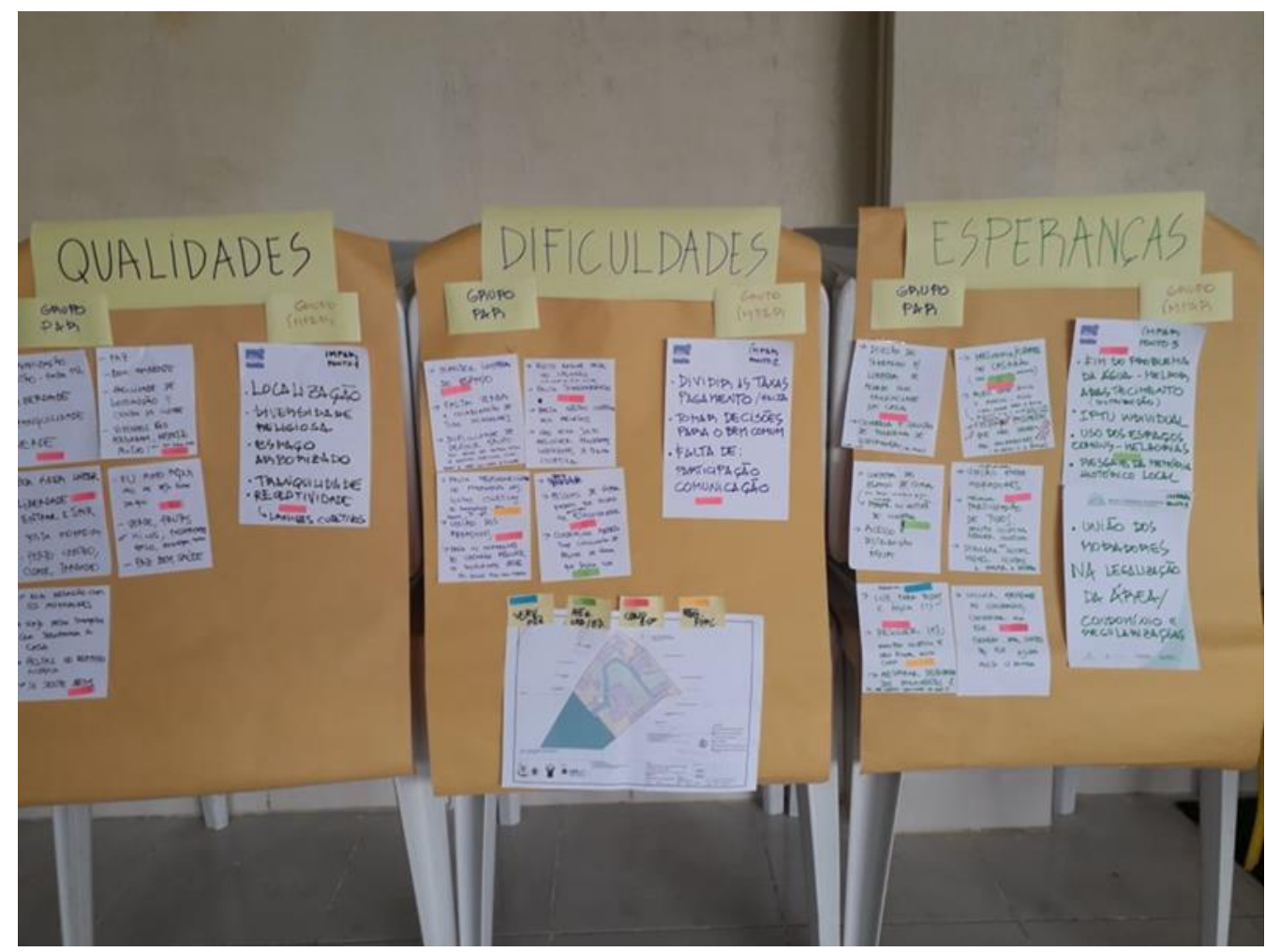

Figura 1 - Quadro realizado na reunião do dia 18 de maio de 2019. Fonte: Acervo do Projeto ATHIS.

A pesquisa-ação, como sustenta Tripp (2005, p. 447), ao mesmo tempo altera o que está sendo pesquisado e é limitada pelo contexto e pela ética da prática. Nas reuniões da equipe e com os moradores, interferíamos com nossas posições no esforço de construir respostas para a gestão coletiva do fundiário local. Nossas posições nem sempre coadunavam com as dos nossos interlocutores. Compreendemos que, tanto no contexto prático do projeto quanto na pesquisa em si, era primordial respeitar saberes e demandas dos diferentes sujeitos da pesquisa.

Nesse contexto, o presente artigo pretende descrever e debater os desafios da gestão de propriedades coletivas no contexto brasileiro a partir do caso específico da Chácara do Catumbi. Nossa hipótese central - compreendida como diretriz, que tem a função, como sublinha Thiollent (2011, p. 99), de orientar o questionamento e buscar as informações relevantes - se assenta sobre a ideia que políticas e projetos de regularização voltados para propriedades coletivas devem se basear sobre a multiplicidade de formas de conceber os aspectos coletivos da propriedade. Retomaremos, em primeiro lugar, o debate em torno do comum em questões envolvendo os direitos de propriedade e a informalidade urbana no Brasil. Em seguida, descreveremos o caso da Chácara do Catumbi para, finalmente, debater os principais desafios da gestão coletiva da propriedade pelos moradores desse local.

\section{I - A questão dos comuns, a informalidade urbana e a propriedade coletiva no Brasil}

O conceito de recursos comuns é aplicado também para o fenômeno urbano como forma de gestão comunitária, alternativa às regras de mercado e à planificação pública estatal (Obregon, 2016, p. 17). 0 
principal objetivo é dar respostas mais eficientes às demandas sociais, compartindo e gerindo bens, conhecimentos e espaços, que configuram cenários urbanos mais igualitários.

Nesse contexto, a reflexão sobre o comum aborda também a questão fundiária, o que demanda uma reflexão prévia sobre o próprio conceito de propriedade. Rosa Congost (2003) prefere usar o termo de "direitos de propriedade", o que daria um aspecto mais flexível na compreensão do fenômeno. Congost constrói essa categoria partindo do entendimento que relações de propriedade são relações sociais que ultrapassariam aspectos legais ou dispositivos institucionais, abrindo, assim, um fecundo campo para a reflexão sobre a pluralidade das formas de usos de uma determinada propriedade, em seus diferentes tipos.

Esse tipo de compreensão se opõe à mentalidade contemporânea liberal de propriedade, uma vez que a propriedade pode mudar e se desenvolver mesmo quando não acompanhada pelo arcabouço legal e jurídico de uma determinada sociedade, ou seja, as formas de organização do fundiário são variadas e dinâmicas. Não existiu (e nem existe) uma única forma de compreender a propriedade, mas várias, que variam conforme o contexto histórico vivenciado, ou seja, é preciso compreender a propriedade também como uma construção sociojurídica e não como algo dado (Carvalho \& Siqueira, 2019, p. 57). Relativizar as formas de compreender a propriedade é importante para identificar formas híbridas, coletivas, fragmentadas e muitas vezes com direitos superpostos e distintos. Como sublinha Hoofs (2010, p. 27), a propriedade não pode ser definida com precisão porque seu significado e alcance se adaptam às necessidades sociais.

Apesar de uma reflexão liberal hegemônica sobre a propriedade, Rosa Congost (2003) afirma que há alterações no direito de propriedade mesmo quando o direito positivo não as acompanha (Congost, 2003, p. 75). Isso nos parece uma chave analítica importante para compreender que muitas estruturas informais de gerir a propriedade fundiária podem ser compreendidas como novas formas de responder às demandas sociais e não necessariamente como algo ilegal. Nesse sentido, Christian Barrère (2001) identifica que os modelos formais ou informais de gestão da propriedade são conjuntos complexos de condições de uso de recursos raros. De forma implícita ou explícita, há sempre um sistema de direitos de propriedade que definem a natureza e os limites de uso dos bens fundiários.

Basudeb et al. (2006, p. 2) explicam que durante os anos 1990 surge a ideia de trabalhar os arranjos informais do ponto de vista de regimes de propriedade comum. A associação do informal ao caótico e ao desestruturado muitas vezes deslegitimou práticas distintas de gestão do fundiário, o que favoreceu tipos de intervenções, que muitas vezes conduziram a medidas desastrosas ${ }^{5}$. Mendes (2012, p. 44) reafirma essa posição, afirmando que não se deixou qualquer espaço possível para costumes alheios ao direito de propriedade de cunho liberal. Tais práticas são consideradas ilegalidades e, a despeito da magnitude da ofensa, passam a representar um risco para a sociedade.

Isso obviamente se manifesta também nas formas de gerir os direitos de propriedade dentro das favelas. A dimensão política da informalidade nos remete também aos aspectos políticos da própria definição variável dos seus contornos. Dependendo dos grupos envolvidos, certas práticas podem ou não ser associadas à informalidade ou serem socialmente legitimadas mesmo apresentando alguma forma de irregularidade jurídica. As particularidades da gestão dos direitos de propriedade influenciaram as formas de consolidação da informalidade. Assim, muito mais do que ser um desvio ou uma excrescência, a informalidade fundiária se consolidou junto com um complexo aparato de registro dos direitos de propriedade. Assim, apesar da complexidade registral, jurídica e urbanística para registrar direitos de propriedade, a maior dificuldade continua sendo os aspectos políticos, envolvendo as práticas informais e os direitos de propriedade.

As políticas de regularização fundiária das favelas consolidaram-se no Brasil, como política urbana, a partir do início da década de 1980. Apesar da construção gradual de uma profunda reflexão sociojurídica sobre a regularização fundiária no país, o balanço registrado dos programas de legalização do solo é, todavia, ao menos por enquanto, extremamente limitado. A promulgação da Constituição Federal em 1988 trouxe um outro dinamismo para a questão, sobretudo após a promulgação do Estatuto da Cidade (lei no 10.257 de 2001) (Brasil, 2001, 2016).

\footnotetext{
5 Defendemos centrar a reflexão da dimensão espacial do informal a partir de uma abordagem política das práticas informais. Sobre a discussão sobre informalidade urbana, ver, por exemplo: Roy, 2011, Macfarlane, 2016, Collectif Inverses, 2016, Gonçalves, 2017 e Gonçalves et al., 2018.
} 
Apesar das medidas progressistas do capítulo das políticas urbanas da Constituição Federal (artigos 182 e 183), a propriedade privada continuou sendo o aspecto central da política de habitação, mantendo alguns elementos consolidados desde o golpe de 1964, ou seja, controle limitado sobre o mercado de aluguel e pouquíssimas experiências de habitação social que não fossem via acesso à propriedade privada. Apesar do movimento da reforma urbana ter defendido uma melhor partilha da propriedade privada, pouco se refletiu sobre outras formas de direitos de propriedade (Gonçalves, 2019).

São raras, no Brasil, experiências de políticas de habitação social através de locação social, como acontece na França desde o início do século passado (Stébé, 2016). As experiências de cooperativas no Brasil tampouco questionam a propriedade privada, como foi o caso das propriedades coletivas da política de cooperativas habitacionais no Uruguai (Valadares, 2018). Os casos mais emblemáticos de propriedade coletivas no Brasil são as propriedades especiais constitucionais de caráter de uso ou posse coletivo, como as reservas indígenas, as propriedades quilombolas ou as reservas extrativistas. Para Pilati (2009, p. 107), a Constituição Federal de 1988 estabeleceu as linhas fundamentais do direito étnico, nos artigos 215 e 216, e criou, assim, modelos especiais de propriedade, que fogem tanto do padrão do Código Civil quanto do escopo do direito administrativo da propriedade pública. Para Motta (2017, p. 10), as definições mais recorrentes sobre comunidade tradicional têm apostado na noção de que ela se constitui por grupos que de alguma forma - tendem a preservar o território que habitam. 0 conceito seria "propositadamente abrangente". Não se trata, nesses casos, de apropriação de terra por indivíduos ou pluralidade de sujeitos privados, como analisaremos no caso da usucapião urbana coletiva, por exemplo.

A outra possibilidade de propriedade coletiva seria justamente a propriedade derivada da sentença declaratória de usucapião especial coletiva urbana. Segundo o artigo 183 da Constituição Federal, todo ocupante de terrenos - que não é proprietário de um outro imóvel urbano ou rural - pode adquirir a propriedade do solo pela Usucapião, se ele aí habita há mais de cinco anos, se o proprietário não interveio para recuperar o terreno durante este período, e à condição de que a superfície do imóvel não ultrapasse 250 metros quadrados. A lei do Estatuto da Cidade admitiu a usucapião também na forma coletiva, quando não for possível individualizar os lotes dos diferentes ocupantes.

É preciso ajuizar uma ação de usucapião e a propriedade coletiva só pode ser registrada com a sentença declaratória da usucapião com trânsito em julgado. Segundo Pereira (2011) e de acordo com o art. 10ํㅜ , inciso $4^{\circ}$ do Estatuto da Cidade, a usucapião coletiva forma um condomínio especial, que é, por regra, indivisível e não pode ser extinto. No entanto, uma vez constituído, é possível extingui-lo por deliberação tomada por dois terços dos condôminos. 0 novo condomínio mescla espaços de ocupação exclusiva, que deve se voltar para a moradia (mesmo que seja possível aceitar usos mistos) com espaços de ocupação propriamente coletiva.

Fica claro que o objetivo da Usucapião especial coletiva urbana não se volta para a tutela da propriedade individual, ensejando, pois, a necessidade de adoção de disciplina própria. Uma primeira dificuldade de implementar a usucapião é a necessidade de uma decisão judicial, o que pode levar anos e mesmo décadas para o trânsito em julgado. Outra dificuldade é implementar a usucapião coletiva em ocupações muito numerosas, por causa da dificuldade de formulação da convenção do condomínio especial com centenas ou mesmo milhares de pessoas envolvidas.

\section{II - A História da Chácara do Catumbi e o debate em torno da gestão da propriedade coletiva após a sentença da Usucapião Especial Coletiva Urbana}

Situado na Rua Emília Guimarães, no 67, no bairro do Catumbi, no Rio de Janeiro, o imóvel foi originalmente de propriedade do Barão de Chichorro, onde foi construído, no século XIX, um solar para sua moradia. Segundo petição inicial do processo, a propriedade era uma chácara produtiva ${ }^{6}$. Antônio Pinto Chichorro da Gama, segundo informações do portal eletrônico do Supremo Tribunal Federal, nasceu em abril de 1800, na cidade

\footnotetext{
${ }^{6}$ Petição inicial, datada de 23 de maio de 2006, do Processo nº2006.001.067354-4 da 7ạ Vara Cível da Comarca da Capital do Rio de Janeiro, p. 6.
} 
Nazaré, na Bahia. Formou-se em Direito na Universidade de Coimbra. Regressando ao Brasil, teve uma vida pública extremamente ativa. Trabalhou como juiz e, posteriormente, desembargador até ser nomeado, em 1960, ministro do Supremo Tribunal de Justiça, onde se aposentou em 1875 (Lago, 2001, p. 98).

Liberal, militou na política como deputado eleito por Minas Gerais (1830-1833/1834-1837) e exerceu um papel central no movimento praieiro de Pernambuco quando foi presidente dessa província, em 1848 (Carvalho \& Dornelas, 2008). Foi nomeado senador, pelo imperador, da província do Rio de Janeiro em 1865. Além de ter sido presidente das províncias do Espírito Santo, Alagoas e Pernambuco, foi Ministro de Estado no período da regência. Faleceu na cidade do Rio de Janeiro no dia 10 de junho de 1887, sendo sepultado no Cemitério de São João Batista.

A propriedade era composta de uma casa principal e de um vasto terreno. Os moradores Lucio e Carla nos relataram que a senzala se localizava no subsolo da casa, onde encontraram muitos objetos relacionados à escravidão, como correntes. Eles moraram por um tempo no casarão, mas atualmente possuem suas moradias em construções mais recentes, levantadas no entorno do casarão. Em uma das visitas, outro morador, Gegê, nos fez mostrar ainda o resquício de uma corrente de ferro, onde, segundo ele, as pessoas escravizadas eram acorrentadas. Carla, por sua vez, que mora em uma construção no entorno do casarão, provavelmente onde se situava o estábulo da chácara, também nos relatou vestígios de artefato relacionados à escravidão quando fez obras nos fundos do seu terreno.

Os relatos que recolhemos dos moradores não é muito linear depois da morte do Barão de Chichorro. Lucio e Carla nos relataram que a propriedade foi paulatinamente loteada e vendida. A casa principal (figuras 2 e 3) foi finalmente comprada por um comerciante espanhol, Rafael Garcia, que alugou a casa principal para várias famílias. Cacilda Lourenço Garcia, sua esposa, continuou a explorar o local após a morte do comerciante espanhol. Carla, que conheceu Dona Cacilda, relata que ela era extremamente severa no cuidado da propriedade e na cobrança dos aluguéis.

Lucio e Carla afirmam que as herdeiras de dona Cacilda, a quem eles pagavam aluguel, não demonstraram interesse pela área, deixando-a abandonada por vários anos. Em 1994, Lucio nos relata que o muro que separava o terreno da Chácara do Catumbi das favelas da Mineira e de São Carlos caiu após fortes chuvas. Como o muro não foi reconstruído, a parte superior do terreno da Chácara acabou sendo ocupada por moradores dessas favelas ${ }^{7}$. Tendo em vista a consolidação dessa ocupação, Carla nos confirmou que os moradores da casa principal decidiram parar de pagar os aluguéis aos herdeiros de Cacilda, mas continuaram a pagar o imposto predial da propriedade e a promover a manutenção da casa principal.

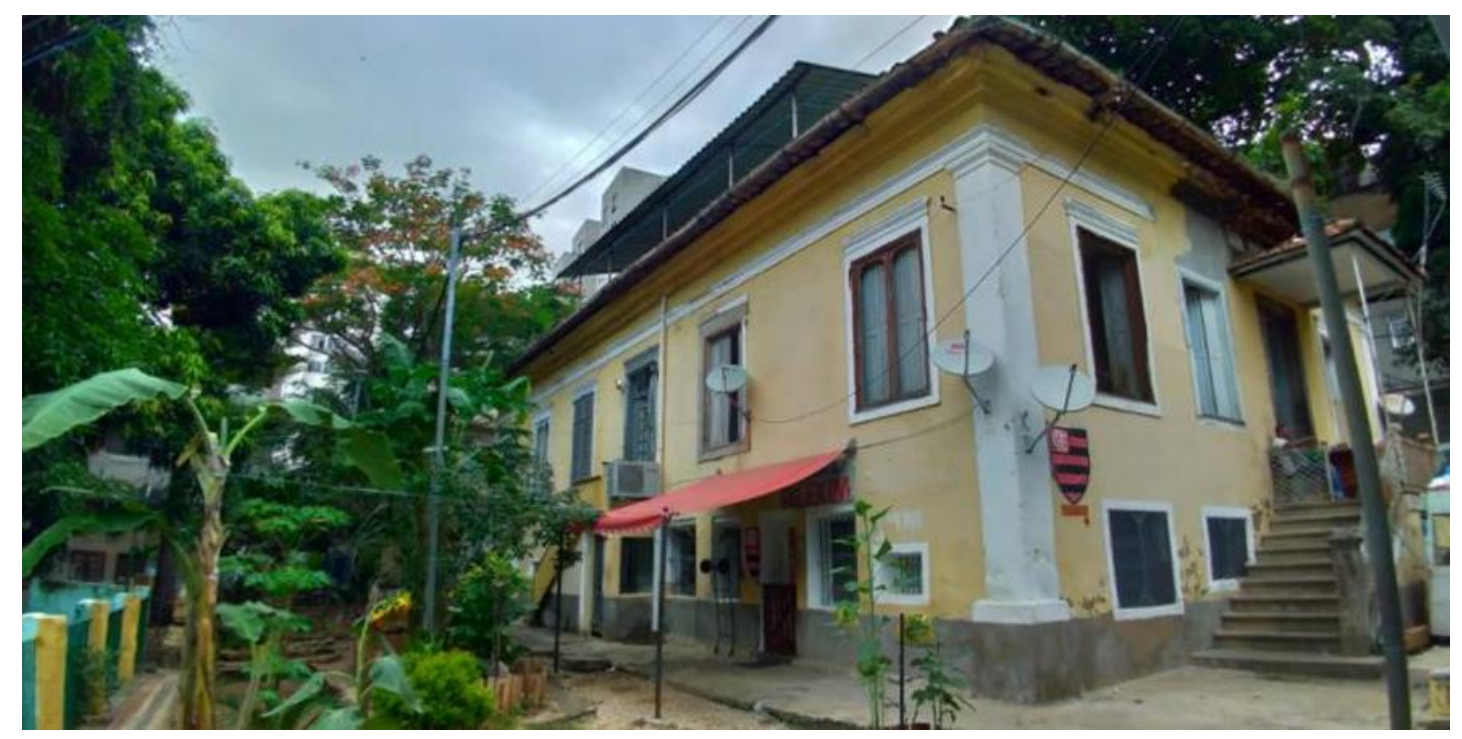

Figura 2 - O casarão da Chácara do Catumbi. Fonte: Acervo Projeto ATHIS.

7 A informação dessa ocupação consta na contestação, datada de 06 de junho de 2009, do Processo no 2006.001.067354-4 da 7ạ Vara Cível da Comarca da Capital do Rio de Janeiro, página 243. 


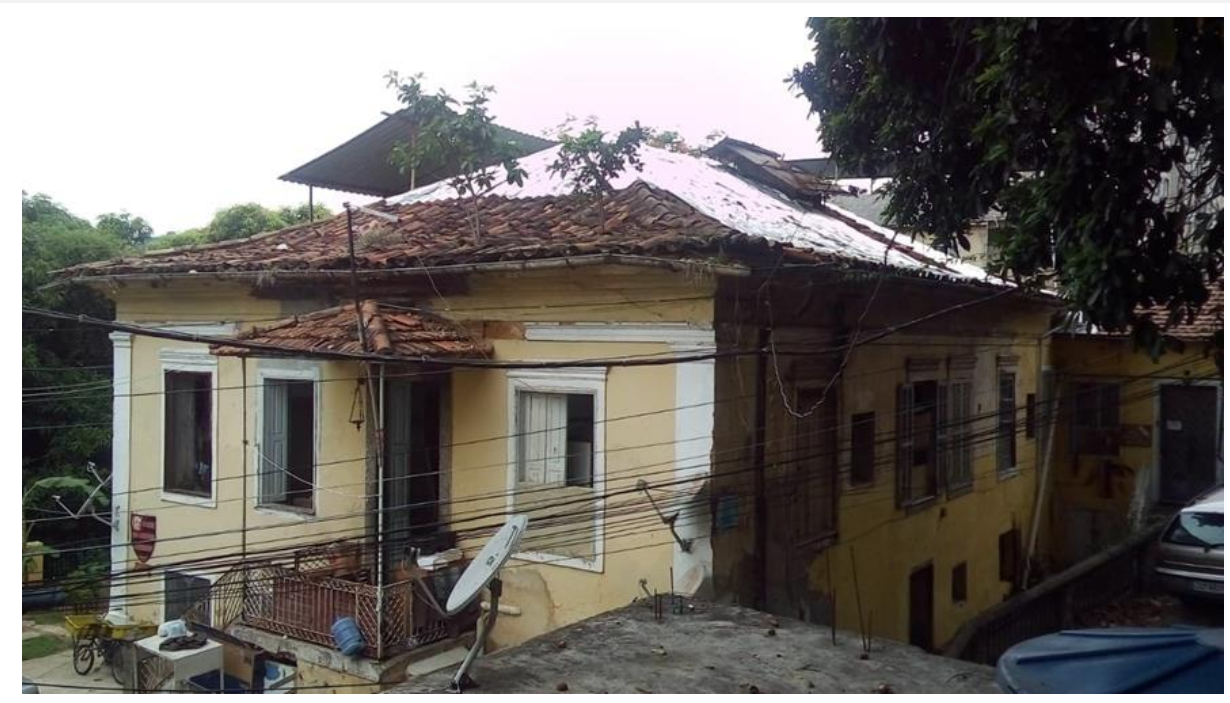

Figura 3 - O casarão da Chácara do Catumbi. Fonte: Acervo Projeto ATHIS.

Em 2002, os moradores foram ameaçados por uma ação de desapropriação da prefeitura com o objetivo de instalar o Centro de Referência do Samba Carioca no contexto do projeto Favela Bairro do Morro da Mineira (Benicio, 2002, p. 2). Diante da ameaça iminente de expulsão, os moradores se articularam politicamente, contatando diferentes políticos. A prefeitura acabou abandonando o projeto de criação do centro de referência no local ${ }^{8}$. Mesmo assim, os moradores, com o apoio da Fundação Bento Rubião, propuseram alguns anos depois, mais precisamente no dia 24 de maio de 2006, uma ação de usucapião especial coletiva9. Diante das dificuldades financeiras da Fundação Bento Rubião, a Pastoral de Favelas da Diocese do Rio de Janeiro acabou assumindo o processo um pouco antes do seu término.

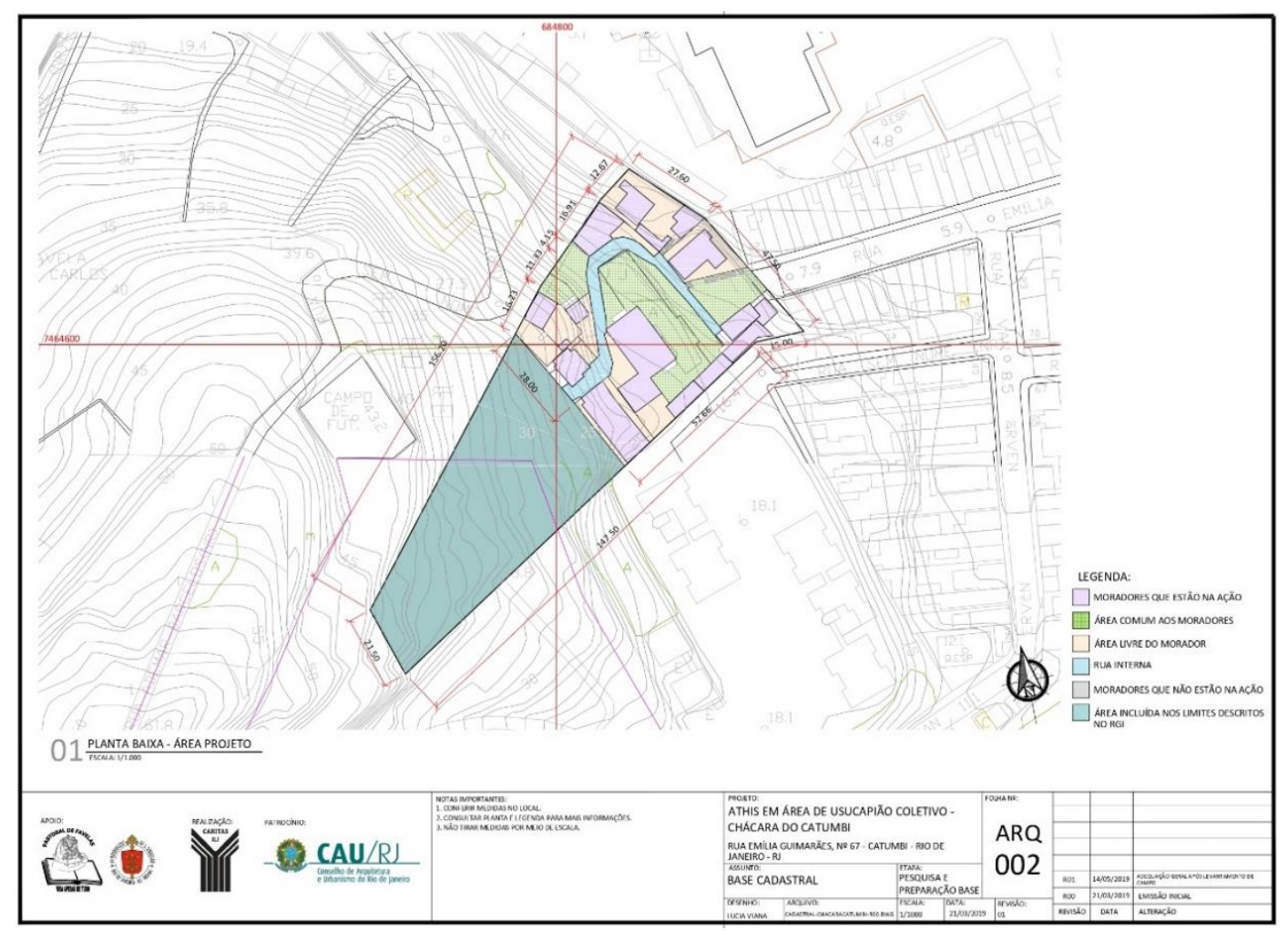

Figura 4 - Área total da propriedade (em cores a área usucapida da Chácara do Catumbi). Fonte: Acervo Projeto ATHIS.

\footnotetext{
${ }^{8}$ Carla possui um dossiê com inúmeras cartas de apoio recebidas de políticos de espectros políticos variados, que foram contatos por seu falecido marido para auxiliarem na luta contra a remoção pela prefeitura para a construção do Centro de Referência do Samba Carioca.

${ }_{9}^{9}$ Processo judicial no 2006.001.067354-4.
} 


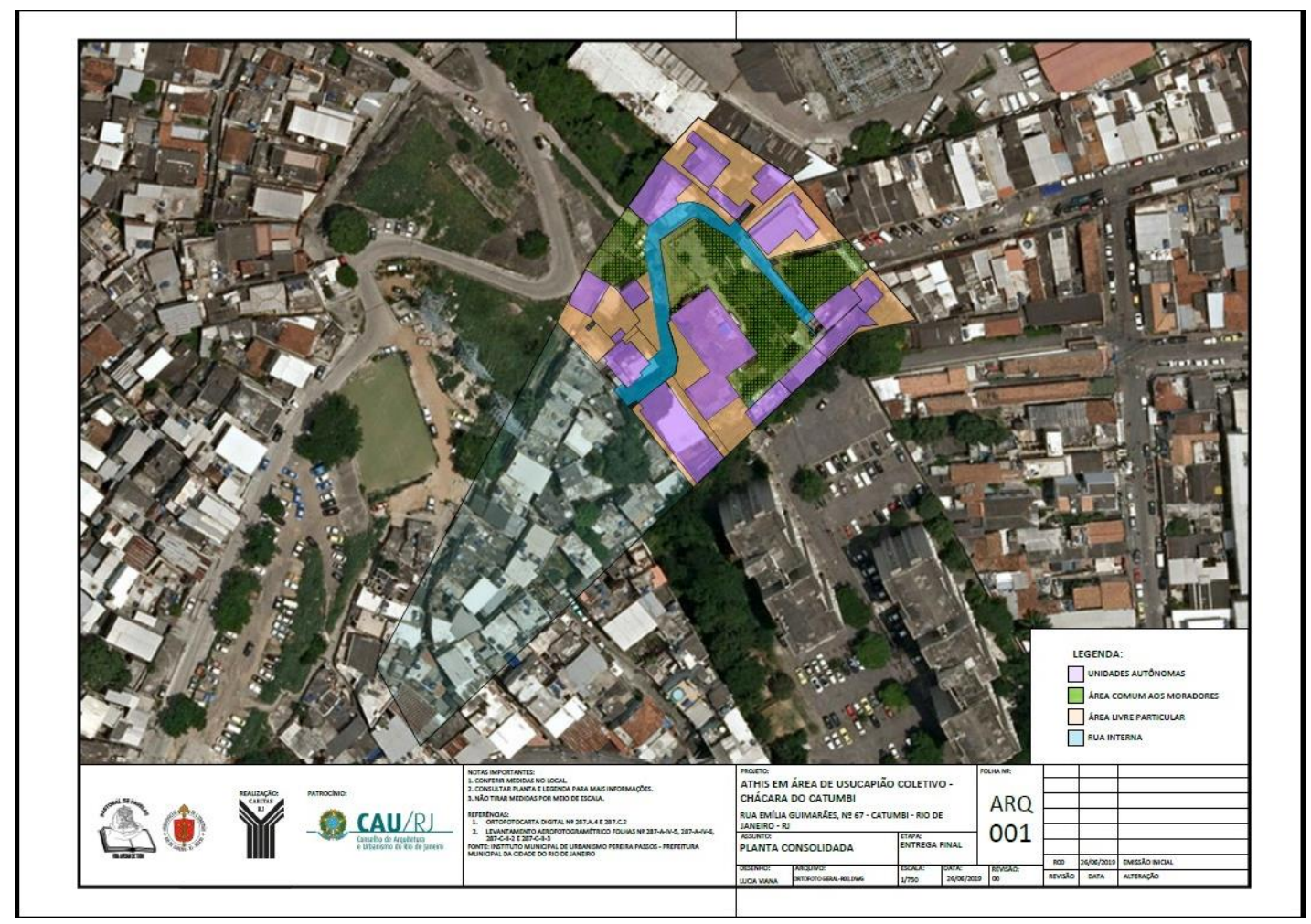

Figura 5 - Foto aérea de toda a propriedade (em cores a área usucapida da Chácara do Catumbi). Fonte: Acervo Projeto ATHIS.

Doze famílias ingressaram inicialmente com a ação, seis famílias se juntaram posteriormente no decorrer do processo. Após 11 anos de batalha judicial, foi dada a sentença pelo juízo da 7a Vara Cível da Comarca da Capital (RJ), declarando o direito a Usucapião Coletiva aos moradores da Chácara do Catumbi. A área usucapida está descrita nas figuras 4 e 5.0 direito foi negado a uma das famílias, pois já possuía outro imóvel e a usucapião especial urbana, individual ou coletiva, não pode ser concedida para aquele que já possui outro imóvel. A decisão concedeu, assim, 1/17 do terreno para cada morador.

A sentença declaratória de usucapião foi finalmente registrada no 7o Ofício de Registro de Imóveis do Rio de Janeiro. Com a Ação de Usucapião, foi estabelecido um condomínio especial com iguais frações ideais, independente da área ocupada, para posterior formação e registro da convenção coletiva do mencionado condomínio, que fixará os direitos e obrigações dos moradores e estabelecerá os espaços de uso coletivo e aquele de uso privado de cada família.

Além da casa principal, a área conta com 12 edificações, totalizando 27 moradias e o terreno, dos quais 23 moradores se dizem proprietários com 4 casas ocupadas por inquilinos. Esses 23 proprietários vinham partilhando os valores do IPTU, assim como os diferentes custos de manutenção da área, sobretudo aqueles relacionados com o funcionamento da bomba de água. No entanto, o pagamento do IPTU de 2020 foi dividido por 27 cotas, incluindo no pagamento os inquilinos também. Apesar de alguns moradores não terem ingressado no processo ou terem adquirido a moradia posteriormente à sentença, observamos, em todas as reuniões, que não há questionamentos pelos moradores locais sobre os direitos de propriedade daquele que possuem moradias no local, mas não integraram a lide. A ideia é integrá-los como proprietários no momento do registro da convenção de condomínio, assim como de formalizar as transações realizadas desde a sentença e que não foram ainda registradas no RGI.

Através da Figura 6, podemos identificar o perfil socioeconômico das famílias entrevistadas. 


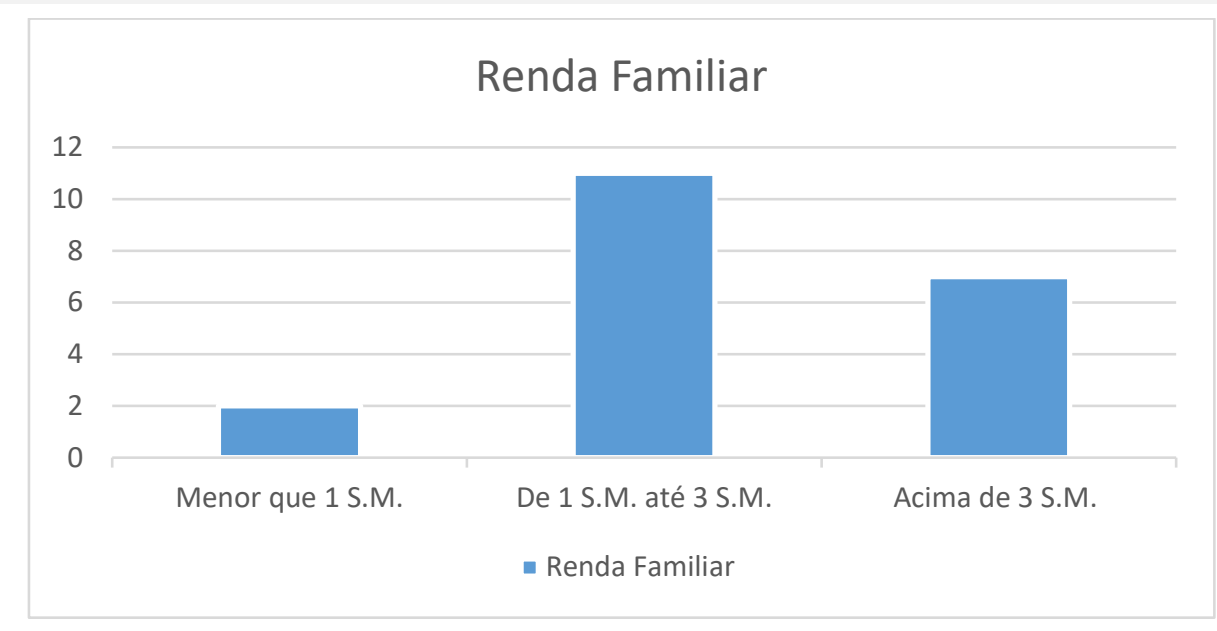

Figura 6 - Renda familiar dos moradores. Fonte: Acervo Projeto ATHIS.

A maioria das famílias apresentam uma renda mensal de até 3 salários mínimos ${ }^{10}$. Uma característica que nos chama atenção, em relação a renda, é que $45 \%$ das famílias possuem renda variável, já que não possuem vínculo empregatício e trabalham de forma autônoma. Somente 25\% delas possuem vínculo formal de emprego. Os demais, cerca de 30\%, são aposentados ou pensionistas.

Há duas zonas consideradas como de uso coletivo (a zona das árvores, exposta na figura 7 e situada na entrada da Chácara, assim como a área em frente da casa principal, denominada como quadrado, onde acontece a maior parte da sociabilidade do local (festas, cultos religiosos, churrascos e reuniões diversas). Há, ainda, uma servidão, que corta toda a propriedade e permite que os moradores do Morro da Mineira e de São Carlos acessem mais facilmente o bairro do Catumbi.

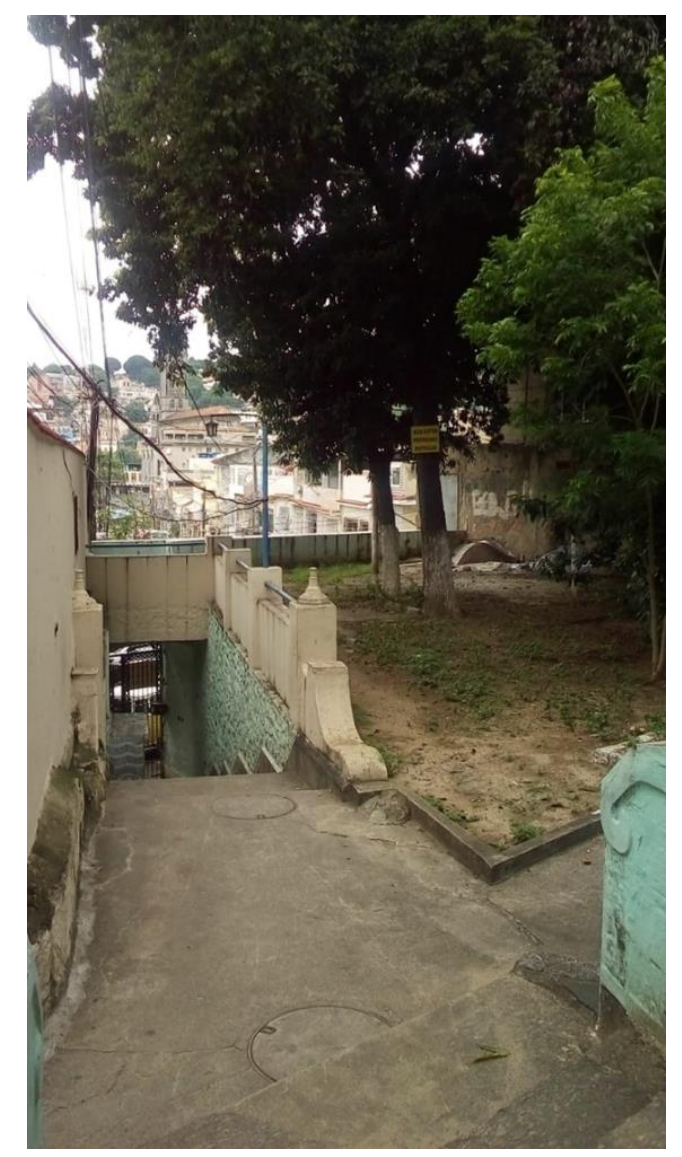

Figura 7 - Zona das árvores. Fonte: Acervo Projeto ATHIS.

\footnotetext{
10 Valor do salário mínimo correspondente ao ano de 2019.
} 
Como os moradores pagavam IPTU e o local não era considerado como parte da favela, os projetos de urbanização da área não integraram os moradores da Chácara do Catumbi à rede local da favela. Como o terreno apresenta um declínio importante, a água da Rua Emília Guimarães não tem pressão para atender a todos os moradores. Assim, os moradores mantêm uma bomba d'água para encher a cisterna do local. É possível observar a dificuldade na gestão coletiva, conforme demonstra a dificuldade em custear coletivamente os custos de manutenção da bomba de água. Essa é, aliás, como veremos a seguir, uma das principais dificuldades apresentadas: a arrecadação e divisão das despesas comuns a todos (manutenção da bomba, IPTU, limpeza da área, poda das árvores).

Para subsidiar a formatação do condomínio especial foram organizadas informações obtidas nas diversas atividades do projeto como: reuniões com moradores (seis reuniões ao todo), levantamentos e visitas na área, cadastro físico-social e entrevistas, bem como em pesquisas e consultas técnicas junto a órgãos governamentais.

A gestão interna do pagamento do IPTU é, de forma unânime, uma das questões que geram mais descontentamento entre os moradores. Observamos, nas reuniões, que a dificuldade em pagar o boleto do IPTU em dia sempre era evocada, já que alguns moradores demoravam a pagar suas partes. Apesar de os moradores reclamarem muito da divisão dos custos do IPTU, observamos que ele acabou sendo o elo de conexão dos moradores. Quando pararam de pagar os aluguéis, eles decidiram manter o pagamento do IPTU por conta própria. Além disso, o pagamento anual desse imposto mantém sempre um movimento coletivo do grupo. A divisão é feita por partes iguais, o que sempre gera questionamentos, já que há diferenças importantes do tamanho das casas. Outro problema é que possíveis atrasos no pagamento podem acarretar juros e mesmo colocar em risco a propriedade como um todo, caso a prefeitura promova uma execução judicial de uma pretensa dívida. Apesar do aspecto coletivo do título de propriedade, quando perguntados sobre o que pensam em relação ao IPTU ser cobrado de forma coletiva, $75 \%$ desaprovam e preferiam que fosse individualizado.

O principal argumento de quem defende que o IPTU seja individual é de que, dessa forma, acabará com a dificuldade de recolhimento do dinheiro. Seria cobrado de uma forma justa, já que da forma que é feito atualmente não há proporcionalidade entre os moradores em relação com o tamanho das casas de cada um. Quem tem preferência em manter o pagamento coletivo do IPTU afirma que o valor será bem maior se a cobrança for individualizada, já que a cobrança atual não comporta a totalidade das construções atualmente existentes. Como o IPTU é cobrado somente pela superfície da casa principal, ao se inserir na base fiscal as demais construções, aumentará consideravelmente o valor do imposto.

Outra possibilidade seria manter o pagamento coletivo do IPTU, mas somente diferenciar, na futura convenção de condomínio, os valores das cotas de cada um de acordo com o tamanho das casas. Essa variação das cotas de pagamento do IPTU não envolveria necessariamente um questionamento quanto à cota parte de cada condômino da propriedade coletiva, ou seja, a propriedade continuaria sendo coletiva e a diferenciação dos valores seria indicada na convenção sem alterar as porcentagens que cabe a cada um da propriedade total. Observamos que esse debate não foi aprofundado no decorrer do projeto junto aos moradores. O IPTU de 2020, como citamos anteriormente, foi dividido por 27 pessoas, incluindo também as unidades alugadas, tendo os inquilinos arcados também com uma cota-parte do valor.

Em relação aos espaços comuns, há consenso entre os moradores de que por serem coletivos não podem ser utilizados de forma privada, principalmente para novas construções. Foi discutido também nas reuniões a possibilidade de fechamento da propriedade com portões, bloqueando a servidão, que permite aos moradores do Morro da Mineira acessar o Bairro do Catumbi mais rapidamente. Entretanto, todos entenderam que esse fechamento seria impossível, já que suscitaria muitas críticas dos moradores da favela, que poderiam inclusive reclamar junto ao tráfico de drogas.

Embora esse fechamento provavelmente nunca aconteça, esse debate trouxe algumas questões interessantes sobre a relação dos moradores da Chácara com os moradores da favela da Mineira. Observamos que, para os moradores mais antigos da Chácara, há um discurso de distinção em relação à favela. Lucio e Carla, por exemplo, procuram afirmar que não são favelados e que possuem um título de 
propriedade devidamente registrado. No entanto, para os moradores mais recentes, muitos vindos da própria favela da Mineira e que não participaram do processo de usucapião, essa distinção não existe e compreendem que, apesar do título, a Chácara do Catumbi faz parte da favela. É o caso, por exemplo, de Roberta, que explora uma casa de festa no local, mas ainda possui uma moradia na favela. Apesar de estar vivendo em um pequeno apartamento na casa de festas, sublinha que a Chácara e a favela são a mesma coisa.

No que diz respeito ao uso comercial, apenas dois entrevistados manifestaram-se contra atividades comerciais na área. Alegaram que atividades comerciais podem trazer problemas, como barulho ou a presença de pessoas indesejáveis. Aqueles que concordaram com tais atividades sublinharam, no entanto, a importante de se manter a organização da área e que qualquer nova atividade precisaria da aprovação de todos. Sublinha-se que já existem dois hostels, uma casa de festas e um bar funcionando no local.

A maioria é a favor do estabelecimento de um síndico (75\% dos entrevistados). Os moradores relataram que, anteriormente, havia uma pessoa responsável por arrecadar o dinheiro e pagar as contas e que desviou os recursos para uso próprio. Por esse motivo, alguns ainda acreditam que ter um síndico não é uma boa ideia. Um outro argumento apresentado é o fato de que os moradores são desunidos e que um síndico iria ter dificuldades na administração. No entanto, a maioria defende a presença de um síndico e todos, por unanimidade, se manifestaram favorável em estabelecer uma contribuição mensal para arcar com os custos de manutenção da área.

Em relação à construção nas lajes, $20 \%$ se manifestaram contra, enquanto $80 \%$ são a favor. Os que são contra sublinharam a preocupação com a segurança das construções, enquanto a maioria a favor afirma ser melhor "subir" a casa que invadir espaços coletivos. Nesse quesito, não se observa uma distinção da lógica de ocupação imobiliária das favelas (Cavalcanti, 2009; Gonçalves, 2012): verticalizar ajuda a abrigar uma nova família e/ou auxilia no sustento da família com a cobrança de um aluguel.

\section{III - Concluindo em torno do debate sobre a gestão da propriedade coletiva}

Além da observação dos próprios moradores, procuramos observar também a atuação da equipe no decorrer do projeto. Muitos dos membros do projeto de Assessoria técnica são técnicos experientes e militantes do direito à moradia. Foi interessante observar suas concepções da propriedade coletiva e como em muitas situações elas divergiam das práticas mais funcionais e pragmáticas dos moradores. Em algumas reuniões de equipe, foi sugerido que a convenção de condomínio previsse maior controle das transações imobiliárias das benfeitorias no interior da propriedade coletiva, exigindo, por exemplo, que toda e qualquer transação deveria ter o consentimento de todos os demais moradores. A ideia seria dar um caráter mais coletivo na gestão direta do fundiário e evitar possíveis processos de gentrificação da área ${ }^{11}$.

Observamos que tais ideias nem eram objeto de análise pelos moradores, já que não se coadunavam com as práticas locais, sobretudo diante da possibilidade de comercialização de suas casas ou da criação de novas unidades a partir do uso da laje. Os moradores mais pobres não entendem o morar na cidade como mero exercício de sobrevivência. Eles tiram todo o partido possível das situações que vivem e tentam reproduzir, à sua escala, os mecanismos do sistema urbano/capitalista ao qual estão submetidos. Como já sublinhava Santos (1982), os moradores pobres do Rio de Janeiro têm sido pouco escutados sobre onde e como morar e, quando podem, revelam uma clareza típica baseada em uma espécie de "ideologia do quotidiano", a mais pragmática possível.

Isso nos fez refletir sobre o papel da equipe técnica e como construir processos participativos sem um caráter impositivo. É necessário articular o saber dos moradores, oriundo de suas experiências cotidianas, com o saber técnico/acadêmico (Baremblitt, 1992). Como analisa Le Roy (1999), projetos de regularização fundiária precisam conciliar a institucionalização com a funcionalidade das práticas locais. 0 caráter

\footnotetext{
${ }^{11}$ Há um esforço em pensar novas formas mais coletivas de gestão do fundiário, como a promovida pela ONG Comunidades Catalisadoras (ComCat), que vem procurando discutir a implementação de um Community Land Trust (CLT) em favelas do Rio de Janeiro. Alguns dos técnicos do projeto ATHIS estão direta ou indiretamente envolvidos com a iniciativa da ONG ComCat. Sobre as possibilidades de aplicação do CLT no Brasil, ver Ribeiro (2020).
} 
coletivo da demanda da área foi o que permitiu que os moradores ali ficassem e que a área mantivesse, ao menos por enquanto, uma melhor qualidade urbanística do que o restante da favela, com áreas menos densamente povoadas e com a presença de áreas de uso coletivo, que são cada vez mais raras em áreas de favelas. É preciso, assim, compreender as iniciativas coletivas de acordo com as particularidades locais sem impor regras universais e muitas vezes distantes de tais práticas.

A reflexão em torno do comum está baseada no uso dos recursos, mas não podemos abandonar, no caso estudado, a importância do valor de troca do bem. Ao invés de modelar formas abstratas de gestão coletiva de recursos comuns, seria importante dialogar com as práticas existentes e encontrar mecanismos de conciliação do valor de uso e de troca. Os trabalhos de Santos criticaram interpretações limitadoras da periferia somente como a expressão espacial da superexploração do trabalho e procuraram compreender a casa do pobre não só pelo seu valor de uso mas também pelo de troca, ou seja, essa casa era abrigo, mas também poderia ser transacionada no mercado com possibilidade de lucro (Santos, 1980, 1982).

Essa questão ficou muito patente na reunião que tivemos no dia 01/06/2019, quando fizemos uma dinâmica de caminhar na área com os moradores para definir os espaços coletivos e aqueles de uso privativo. Foi muito discutido o caso de expansão e verticalização da casa de Dona Raquel. Ela possui uma das menores casas do local e pretende aumentá-la de acordo com seus recursos, dentro do movimento gradual de autoconstrução nas favelas. Se era reconhecido por todos o seu direito de aumentar sua casa, a discussão foi por vezes tensa quanto aos possíveis impactos que sua nova construção poderia provocar nas moradias próximas à sua casa. Os moradores evocavam não somente a diminuição de qualidade de vida, já que teriam uma construção diante de suas janelas, mas também era evocada a possível perda de valor dos imóveis onde moravam, ou seja, não há como não levar em consideração que possíveis configurações da gestão fundiária local têm que comportar também a função de troca das moradias. Nesse mesmo dia da caminhada, ouvimos de muitos moradores o interesse em aumentar suas casas, inclusive os do casarão, o que poderia descaracterizar a própria construção, que sempre foi o elemento aglutinador do grupo. 0 casarão exerce uma centralidade nas memórias dos moradores e também uma centralidade propriamente espacial, já que se encontra no centro do terreno e os espaços coletivos o circundam. É preciso consolidar espaços coletivos de mediação entre os usos coletivos e os valores de troca das benfeitorias de forma a evitar a descaracterização da área com uma expansão excessiva de novas construções e transações.

A Chácara do Catumbi é um dos poucos casos de titulação coletiva no país que não está diretamente relacionada com identidades étnicas, como são os casos das terras quilombolas ou das reservas indígenas. A luta pelo título e contra remoções suscitou a mobilização coletiva.

O desafio é como manter tal mobilização. Como podemos analisar no decorrer do artigo, a gestão coletiva do fundiário é conflituosa, tensa e deve ser relativamente flexível às práticas locais. De qualquer forma, conciliar esforços coletivos em uma sociedade cada vez mais pautada em princípios neoliberais e individualistas, como a sociedade brasileira e inclusive em suas áreas mais populares, é um desafio e uma esperança na construção de novas formas de resistência.

\section{Referências}

Baremblitt, G. (1992). Compêndio de análise institucional e outras correntes: teoria e prática (1 ed.). Rio de Janeiro: Editora Record.

Basudeb, G-K, Kanbur, R., \& Ostrow, E. (2006). Beyond informality and formality. In Basudeb, G-K, Kanbur, R., \& Ostrow, E. (Eds.), Linking the Formal and Informal Economy: Concepts and Policies (p. 1-18). New York: Oxford University Press.

Barrère, C. (2001). Pour une théorie critique des droits de propriét. ACTUEL MARX, 29(1), 11-45.

Benicio, E., (2002). “Com medo do despejo”, Jornal O Povo, 30 de julho de 2002.

Bollier, D. (2014). La renaissance des communs. Pour une société de coopération et de partage (1a ed.). Paris: Éditions Charles Léopold Mayer. 
Brum, M. (2018). Opção pelos pobres: a Pastoral de Favelas e a reorganização do Movimento de Favelas no Rio de Janeiro na redemocratização, Estudos Históricos, 31(65), 428-432. http://dx.doi.org/10.1590/s2178-14942018000300006.

Brasil. (2016). Constituição da República Federativa do Brasil: texto constitucional promulgado em 5 de outubro de 1988, com as alterações determinadas pelas Emendas Constitucionais de Revisão nos 1 a 6/94, pelas Emendas Constitucionais nos 1/92 a 91/2016 e pelo Decreto Legislativo no 186/2008. Brasília: Senado Federal, Coordenação de Edições Técnicas.

Brasil. (2001, 10 de julho de 2001). Lei no 10.257, de 10 de julho de 2001. Regulamenta os arts. 182 e 183 da Constituição Federal, estabelece diretrizes gerais da política urbana e dá outras providências. Brasília: Diário Oficial da União, seção 1.

Carvalho, A. M., \& Siqueira, J. do C. A. (2019). Construção Histórica do direito Real de Propriedade: o pensamento de Paolo Grossi. Direito das políticas públicas, 1(1), 53-66.

Carvalho, M. J. M., \& Dornelas, B. A. (2008). A Insurreição Praieira. Almanack braziliense, 4(8), 5-38. https://doi.org/10.11606/issn.1808-8139.v0i8p5-38

Cavalcanti, M. (2009). Do barraco à casa: tempo, espaço e valor(es) em uma favela consolidada. Revista Brasileira de Ciências Sociais, 24(69), 69-80. https://doi.org/10.1590/S0102-69092009000100005.

Collectif Inverses. (Tadié, J.; Morelle, M.; Bautès, N.; Bénit-Gbaffou, C.; Rivelois, J.; Jacquot, S.; Sierra, A.), (2016), L'informalité politique en ville. 8 chercheurs et 9 villes face aux modes de gouvernement urbain, L'espace politique, 29(2).

Congost, R. (2003). Property rights and historical analysis: what rights? What history? Past \& Present, 181(1), 73-106. https://doi.org/10.1093/past/181.1.73.

Gonçalves, R. S. (2012). O mercado de aluguel nas favelas cariocas e sua regularização numa perspectiva histórica. GEOgraphia, 13(26), 114-135. https://doi.org/10.22409/GEOgraphia2011.v13i26.a13627

Gonçalves, R. S. (2017). L'informalité comme une ressource urbaine? Le cas des favelas de Rio de Janeiro. EchoGéo, 11(39), 1-16. https://doi.org/10.4000/echogeo.14872

Gonçalves, R. S. (2019). Reflexões preliminares sobre a reforma urbana e o direito à cidade. In J. G. Souza Junior, N. Saule Junior, A. N. V. Lima, H. B. Frota, K. F. Martins, L. M. S. M. Casimiro, M. E. Cafrune, M. Leão, M. L. P. Fontes, R. Jacovini, S. D. Marques (eds.), Introdução crítica ao direito urbanístico (p. 187-194). Brasília: Editora Universidade de Brasília.

Gonçalves, R. S., Bautès, N., \& Maneiro, M. (2018). A Informalidade Urbana em Questão. Revista O Social em Questão, (42), 926.

Halbwachs, M. (2006). A memória coletiva. São Paulo: Centauro Editora.

Hardin, G. (1968). The Tragedy of the Commons. Science, 162(3859), 1243-1248.

Hoofs, K. (2010). Property rights in legal history. In B. Bouckaert (ed.), Property law and economics (1st ed., p. 5-30). Cheltenham, UK, Northampton, MA, USA: Edward Elgar.

Lago, L. (2001). Supremo Tribunal de Justiça e Supremo Tribunal Federal: dados biográficos 1828-2001. 3. ed. Brasília: Supremo Tribunal Federal.

Le Roy, E. (1999). Le jeu des !ois. Une anthropologie "dynamique" du droit (1ํo ed.). Paris: LGDJ.

Macfarlane, C. (2016). Repenser l'informalité: la politique, les crises et la ville. Lien social et Politiques, 33(76), 44-76. https://doi.org/10.7202/1037065

Mendes, A. F. (2012). Para além da "Tragédia do Comum". Conflito e produção de subjetividade no capitalismo contemporâneo (Tese de Doutorado). Faculdade de Direito, Universidade do Estado do Rio de Janeiro, Rio de Janeiro.

Motta, M. M. M. (2017). Antiguidade é posto: a Aldeia de Imbuí, conflitos e memórias (séculos XIX e XXI). História Unisinos, 21(1), 1-12.

Obregon, D. D. T. (2016). La organización social como promotor urbano frente al fracaso de la Política Nacional de Formalización (1996-2015) (Dissertação de mestrado). Faculdade de Arquitetura e Urbanismo, Pontificia Universidade Católica do Chile, Santiago do Chile.

Ostrom, E. (1990). Governing the Commons. The Evolution of Institutions for Collective Action (1ํa․ ed.). Cambridge: Cambridge University Press.

Pilati, J. I. (2009). Conceito e classificação da propriedade na pós-modernidade: a era das propriedades especiais. Revista Seqüência, 30(59), 89-119. https://doi.org/10.5007/2177-7055.2009v30n59p89 
Pereira, D. Q. (2011). A usucapião especial urbana e a efetivação da função social da propriedade. Revista de Direito da Cidade, 03(02), 245-274.

Ribeiro, T. F. (2020). "Os "Community Land Trusts": potencialidades e desafios de sua implementação nas cidades brasileiras". Revista de Direito da Cidade, 12(1), 609-631.

Roy, A. (2011). Urbanisms, worlding practices and the theory of planning. Planning Theory, 10(6), 6-15.

Santos, C. N. F. (1980). Como projetar de baixo para cima - uma experiência em favela. Revista de Administração Municipal, 27 (156), 6-27.

Santos, C. N. F. (1982). A Desordem é só uma ordem que exige uma leitura mais atenta. Revista de Administração Municipal, ano 29(165), 6-17.

Stébé, J. (2016). Le logement social en France (1a ed.). Paris: PUF.

Thiollent, M. (2011). Metodologia da pesquisa-ação. (18a ed.). São Paulo: Cortez, 2011.

Tripp, D. (2005). Pesquisa-ação: uma introdução metodológica. Educação e Pesquisa, 31(3), 443-466.

Valadares, R. G. (2018). Breve análise da participação de cooperativas nas políticas públicas habitacionais no Brasil e no Uruguai. Redes, 6(2), 187-202.

Editor responsável: Paulo Nascimento Neto

Recebido em 10 mar. 2020

Aprovado em 30 out. 2020 